\title{
Some speculations on the possibility of changes in deep-water renewal in Lake Baikal and their consequences
}

Kipfer, R.* and Peeters, F.

Environmental Physics, Swiss Federal Institute of Technology (ETH) and Swiss Federal Institute of Environmental Science and Technology (EAWAG), 8600 Dübendorf, Switzerland

Tel: (41) 182355 30/31, fax: (41) 182352 10, e-mail: kipfer@eawag.ch, peeters@eawag.ch.

*Correspondence to Rolf Kipfer

\section{Abstract}

Most of the processes that have been identified as responsible for deepwater renewal in Lake Baikal require that the surface water of the lake have higher salinity than the water at a depth of 250 to $400 \mathrm{~m}$. Moderate changes in the temperature of the surface water do not seem to significantly affect the occurrence of vertical advective transport into the deep water. Thus, deep-water renewal in Lake Baikal is probably more strongly affected by changes in salt levels, particle load, and discharge of inflows than by moderate temperature variations due to climate change. Increasing salt levels in the deep water might lead to an increase in the stability of the water column and thus to lower rates of vertical turbulent diffusive transport of, for example, oxygen.

Changes in the rate of deep-water formation would not only have an impact on the ecological state of Lake Baikal but would also affect the biota and its evolution. Deep-water formation may be the 'missing link' connecting internal biological processes in Lake Baikal, especially speciation, with external forcing, linked, for instance, to enhanced salt input due to tectonic activity and climatic change.

Despite the great depth of Lake Baikal (maximum depth. $1632 \mathrm{~m}$ ), oxygen is present throughout the entire water column, indicating rapid deepwater exchange. Tracer measurements demonstrate that up to $10 \%$ of the deep water is renewed annually, and several processes contribute to the deep-water exchange (Fig.1, Weiss et al., 1991; Shimaraev et al., 1993; Imboden, 1994; Kipfer et al., 1996; Hohmann et al., 1997).

Konstanzer Online-Publikations-System (KOPS)

There are only two brief periods, in the course of the year early spring and late autumn, in which significant deep-water exchange can occur. Only 


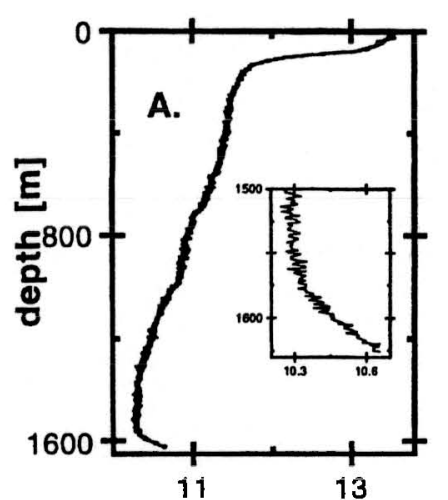

oxygen $\left[\mathrm{mg} \cdot \mathrm{I}^{-1}\right]$
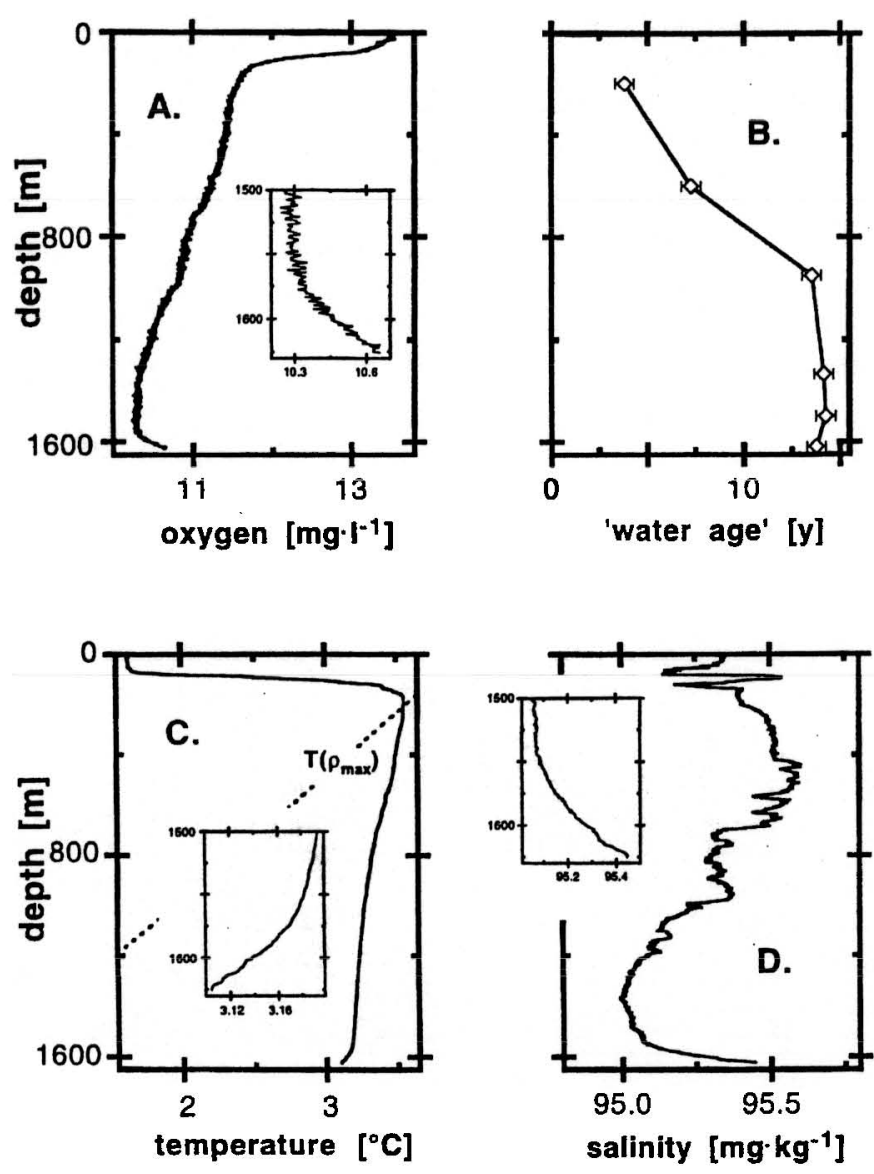

Figure 1. Tracer profiles indicating deep-water exchange in the central basin of Lake Baikal.

A: Lake Baikal exhibits high oxygen levels (above $80 \%$ surface saturation) throughout its entire water column. Small inset: close to the lake bottom the concentration of dissolved oxygen $\left(\left[\mathrm{O}_{2}\right]\right)$ increases with increasing depth. B: 'Water age' (WA) - a measure of the time elapsed since the water was last in contact with the atmosphere - increases with increasing depth. Close to the lake bottom, however, WA decreases with increasing depth. High $\left[\mathrm{O}_{2}\right]$ and low WA in the bottom water indicate that the lower, deepest water is being rapidly replaced by surface water (which is saturated with $\mathrm{O}_{2}, W A \approx 0$ ) via advective transport along the lake boundaries. C/D: Each of the processes that renews deep water leaves characteristic traces in the distribution of temperature and ions in the water column. The young and oxygen-rich bottom water of the central basin of Lake Baikal is colder $(\mathrm{C})$ and contains more particles and ions (D) than the water above it. Water with similar properties can be found in an underwater canyon where the Selenga leaves its delta. In spring, the water in the canyon is colder and richer in particles and ions than the open lake water at equivalent depth. The water in the canyon, therefore, has a greater density than the open lake water, and it sinks along the canyon's bottom boundary to greater depths, where it spreads out to the deepest regions of the central basin. during these seasons are the physical properties of the surface water that control water density (temperature and salinity) similar to the conditions commonly found in the deep water. Moreover, it is only during these periods that the density of surface water is sufficiently large to generate deepwater convection. During the course of five joint Russian-Swiss expeditions several processes were identified as being responsible for deep-water renewal (Tab.1), and these mixing processes lead to significant vertical transport, which may be sufficient to explain the fast deep-water exchange indicated by the tracer mea-surements (Weiss et al., 1991; Peeters et al., 1997; Hohmann et al., 1998).

The temperature of the deep water in Lake Baikal is always close to the temperature at which the surface water reaches its maxi-mum density (Fig.

Table 1. Prominent deep-water formation processes in Lake Baikal and their impact on the physical state of the deep water below $500 \mathrm{~m}$.

\begin{tabular}{|c|c|c|c|c|}
\hline $\begin{array}{l}\text { Process leading to } \\
\text { Deep-water formation }\end{array}$ & Site & $\begin{array}{c}\text { Basin } \\
\text { affected }\end{array}$ & $\begin{array}{l}\text { Impact on } \\
\text { temperature }\end{array}$ & $\begin{array}{c}\text { Impact on } \\
\text { salinity }\end{array}$ \\
\hline River inlets & $\begin{array}{l}\text { Selenga } \\
\text { Delta }\end{array}$ & $\mathrm{CB},(\mathrm{SB})$ & - & + \\
\hline $\begin{array}{l}\text { Thermal bar near } \\
\text { Boldakova (Shimaraev } \\
\text { et al., 1993) }\end{array}$ & $\begin{array}{l}\text { Entire shore } \\
\text { region }\end{array}$ & $\mathrm{CB}$ &,+- & + \\
\hline $\begin{array}{l}\text { Flow over sills, } \\
\text { exchange between } \\
\text { basins(Peeters et al., } \\
\text { 1996; Hohmann et al., } \\
\text { 1997) }\end{array}$ & $\begin{array}{l}\text { Academician } \\
\text { Ridge }\end{array}$ & NB & - & 0 \\
\hline $\begin{array}{l}\text { Hydrothermal activity } \\
\text { (Kipfer et al., 1996) }\end{array}$ & Frolikha Bay & NB & + & + \\
\hline $\begin{array}{l}\text { Vertical turbulent } \\
\text { diffusion }\end{array}$ & everywhere & all basins & + & $?$ \\
\hline Total & & & 'zero' & + \\
\hline
\end{tabular}

$+/-:$ process tends to increase or to decrease the parameter Total : expected integrated effect on Lake Baikal

NB, CB, SB : northern, central and southern basin 
$1(C)$ ), and thus salinity should significantly contribute to the density stratification. The density structure in the region close to the so-called mesothermal maximum (Fig. 1 (D), MTM, $\sim 200 \mathrm{~m}$ deep), which separates the surface water from the deep-water, in particular, is mainly controlled by salinity. Even small salinity differences in this zone regulate the transport of surface water through the MTM towards greater depths during the inverse stratification of the water column that occurs in early spring (Peeters et al., 1996; Hohmann et al., 1997). During this period spatial salinity gradients are the driving force of the verti-cal exchange in the two most active regions of largescale deep-water formation; the Selenga Delta and the Academician Ridge (Fig. 2, Tab. 1).

In the central basin the deepest water has a temperature of about $3.1^{\circ} \mathrm{C}$ Buoyancy-driven transport of surface water at $3.1^{\circ} \mathrm{C}$ down to the greatest depth requires that the salinity of the surface water be about $2 \mathrm{mg} \mathrm{kg}^{-1}$ greater than the salinity of the ambient water at the MTM (200 m depth). Surface water with sufficiently increased salinity and low temperature is provided by the Selenga River discharging into the southern and central basin. In the northern basin deep-water temperatures are above $3.3^{\circ} \mathrm{C}$. To generate buoyancy-driven transport of $3.3^{\circ} \mathrm{C}$ water from the surface down to the greatest depth, the salinity of the surface water need only be $0.8 \mathrm{mg}$ $\mathrm{kg}^{-1}$ greater than at the MTM. Surface water in the central basin has slightly higher salinity than in the northern basin (Fig. 2). At Academician Ridge horizontal transport of central basin water to the north leads to vertical salinity gradients in the northern basin sufficient to drive deep-water convection. Because the difference in salinity between central and northern basin water in the top $300 \mathrm{~m}$ is at most $0.8 \mathrm{mg} \mathrm{kg}^{-1}$, buoyancy driven convection in the northern basin occurs only for water temperatures of $3.3^{\circ} \mathrm{C}$ or above, which explains why the deep water temperature in the northern basin is $3.3^{\circ} \mathrm{C}$ or higher.

The expected overall effects of the different deep-water formation processes on the physical state of the deep water are shown in the last two columns of Table 1. Deep-water formation associated with mixing processes due to hydrothermal activity and thermal bar fronts increases the temperature of the deep-water. However, deep-water renewal related to river inlets and intrabasin mixing causes cold surface water to sink to greater depths. Russian measurements dating back to the beginning of this century suggest that the temperature in the deep water is in a steady state (Shimaraev et al., 1994). Thus, the processes responsible for deep-water renewal must compensate for each other with respect to heat transport.

The situation in regard to salinity is different. All of the pro-cesses that lead to deep-water renewal by large-scale convection seem to increase the salinity of the deep water in Lake Baikal, meaning that salinity should

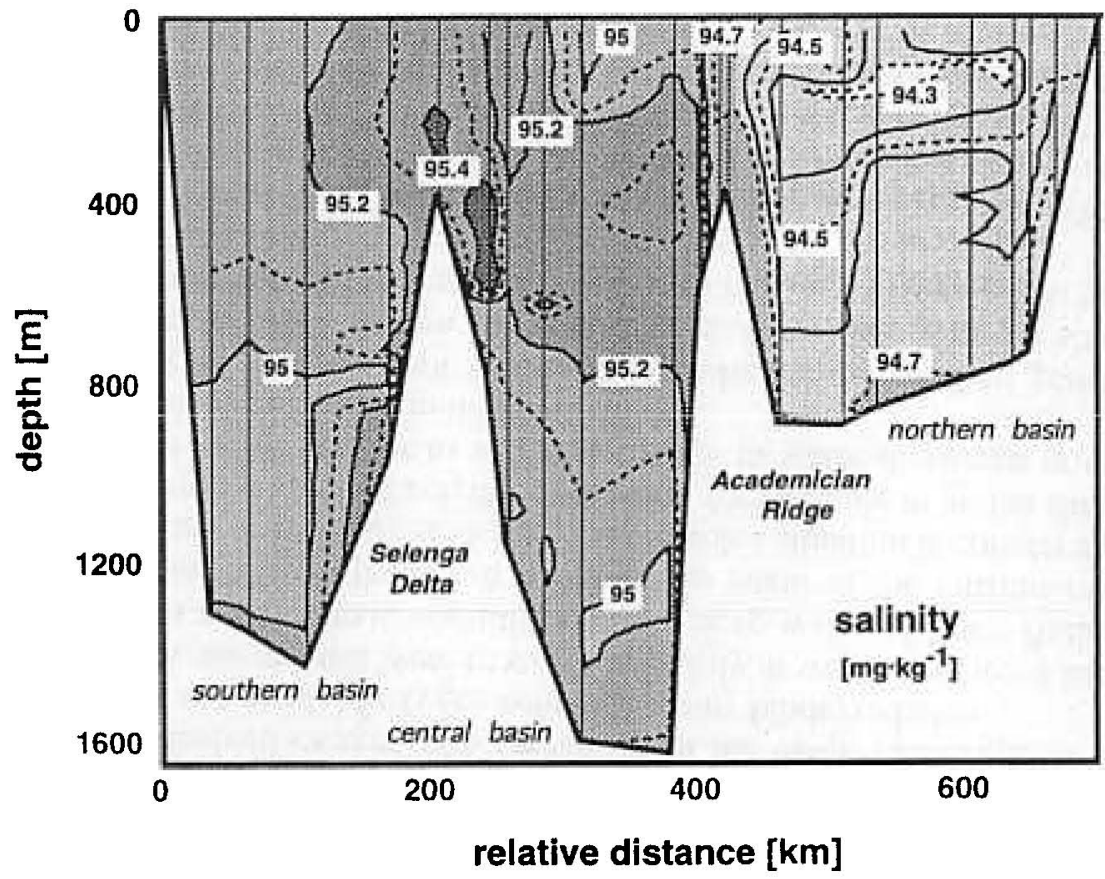

Figure 2. Spatial salinity gradients in Lake Baikal

The density structure $(\rho)$ of Lake Baikal is not determined by temperature $(T)$ alone but by the ion distribution as well (salinity S). Both vertical and horizontal $\rho-$ - T-, and S-gradients develop, and these gradients drive the formation of deep water and lead to the development of a thermo-saline circulation.

Selenga, the major tributary feeding Lake Baikal, drains into the central basin and exhibits an approximately $50 \%$ higher degree of mineralisation than the lake. In contrast, Upper Angara, the second largest tributary, adds freshwater having a low mineralisation level into the northern basin. As a result, the water of the central basin is the most strongly mineralised in Lake Baikal.

The changes in density $(\Delta p)$ resulting from the slight variations in temperature $(\Delta T$ $<0.3^{\circ} \mathrm{C}$ ) in the deep water are extremely small because the gradient $\partial \rho / \partial T$ disappears for temperature close to $4 . \mathrm{C}$. If ions are added to such a water body, however, the density gradients induced by gradients in the ion concentrations might be significant. The calculation of water density in Lake Baikal, is also complicated by the fact that $T$ (pmax) is a function of hydrostatic pressure and decreases rapidly with increasing depth (approx. $2^{\circ} \mathrm{C}$ per $1000 \mathrm{~m}$, Fig. 1).

Dissolved ions play a central role in renewing the deep water of Lake Baikal. While the variation in ion concentrations within each basin is extraordinarily low (e.g. 0.5 mg. $\mathrm{kg}^{-1}$ in the northern basin, Fig. 1) the salinity gradients between basins and between the lake and river water play a key role in transporting cold surface water down to a depth of about $500 \mathrm{~m}$. At this depth the low temperature of the convecting water drives it down to its greatest depth (Weiss et al., 1991; Kipfer et al., 1996; Hohmann et al., 1997; Peeters et al., 1997). 
steadily increase with time. Because the salt levels in Baikalian waters are extremely low, the imbalance in the recent salt budget may be only a transient phenomenon.

Any persistent change in the salt budget of Lake Baikal will directly influence its mixing processes and its deep-water formation, and therefore ultimately affect the water quality and the ecosystem of the lake (Fig. 2, Hohmann et al., 1997).

Despite the generally pristine state of Lake Baikal, signs of subtle changes have recently been detected. For several years river-borne algae adapted to nutrient-rich environments have been migrating from delta regions to the open water. This invasion seems to be indicative of the slowly increasing availability of nutrients. The enhanced nutrient level and the suspected salt non-equilibrium of the lake water could be interpreted as an expression of the rising pres-sure of civilisation around Lake Baikal. Intensification of urbanisation and agriculture may increase soil erosion in the catchment and lead to an increase in nutrient and salt input into the lake through the river discharge. Since the water residence time of Lake Baikal, i.e., the time required for all inflows to refill the lake, is more than 350 years, slight disturbances in water quality are difficult to detect, but remain in the system for centuries. Therefore, the anticipated recent changes in the salt budget of Lake Baikal must be regarded as irrever-sible, and they will affect the ecology of Lake Baikal over several hundred years.

In contrast to salt balance, which is sensitive to small changes in the salt concentration in the inflows, the thermal conditions of the deep water of Lake Baikal can be expected to be fairly insensitive to changes in external heat fluxes, e.g., to variations in climatic conditions. As long as the surface water freezes and thaws regularly, deep-water convection is likely to occur just as it does now. The density anomaly of freshwater, and especially the pressure dependence of the temperature of maximum density $\left(\mathrm{T}\left[\rho_{\max }\right]\right.$, Fig. 1. (C)), in combination with low water temperatures in the deep-water region lead to a barrier of potential energy at the depth of the MTM, between $200 \mathrm{~m}$ and $450 \mathrm{~m}$, which prohibits convection of cold surface water to the deep-water region of Lake Baikal (Peeters et al., 1996). It should be noted that this barrier to convection decreases if the temperature in the deep-water region rises. The potential energy barrier at intermediate depth can only be overcome by water that has greater density, due to increased salinity or an increased load of suspended particles, than the ambient water at the depth of the barrier, or if strong winds cause thermobaric instabilities. The density excess required to allow buoyancy-driven deep-water convection of water at $3.1^{\circ} \mathrm{C}$ and $3.3^{\circ} \mathrm{C}$ is about $1.8 \cdot 10^{-3} \mathrm{~kg} \mathrm{~m}^{-3}$ and $5.8 \cdot 10^{-4} \mathrm{~kg} \mathrm{~m}^{-3}$, and corresponds, for instance, to an increased salinity of $2 \mathrm{mg} \mathrm{kg}^{-1}$ and $0.8 \mathrm{mg} \mathrm{kg}^{-1}$, respectively. Salinity, suspended particle load, and the occurrence of strong winds are the most important parameters responsible for convection, as long as the surface water gets colder than the lowest temperature in the deep water (about $3.1^{\circ} \mathrm{C}$ ), and low enough surface water temperatures are guaranteed if freezing and thawing occurs.

The high oxygen levels in the deep water of Lake Baikal result from the interplay between the fast vertical transport of oxygen linked to the rapid deep-water renewal (about $10 \%$ per year) and very low oxygen consumption, on the order $0.10-0.15 \mathrm{mgO}_{2} \mathrm{l}^{-1} \mathrm{yr}^{-1}$, in the deep-water (e.g. Weiss $e t$ al., 1991; Peeters et al., 1997). Because deep-water renewal is not sensitive to moderate changes in surface water temperature, we speculate that the vertical transport of oxygen in Lake Baikal is not severely affected by moderate climatic changes in temperature. However, changes in the hydrological regime, and especially changes in the salinity and the load of suspended particles in the inflows, might first lead to increased vertical convective transport, and then to a reduction in vertical turbulent diffusion due to increased stability in the deep water, similar to what occurs in Lake Lugano (Wuiest et al., 1992). Under such circumstances, one would expect transport of oxygen by turbulent diffusion to be reduced, which would lead to lower dissolved oxygen concentrations in the deep-water regions of Lake Baikal as a result of oxygen consumption by biodegradation.

If deep-water renewal were to stop completely, it would require at least 100 years to reach anoxic conditions in the deep water of Lake Baikal, assuming that oxygen depletion continues to occur at the current rate, which is on the order $0.10-0.15 \mathrm{mg} \mathrm{l}^{-1} \mathrm{yr}^{-1}$. Such a situation is conceivable only under severe climatic conditions leading, for example to an ice shield covering the entire lake, or to a drastic change in water discharge or salt and particle concentrations in the river inflows.

Data on the abundance of species in Lake Baikal and on their genetic evolution imply that a sudden and distinct mass extinction occurred about 3 million years ago and triggered rapid species radiation (Timosh-kin, personal communication).

Reduced deep-water exchange causing a decline in oxygen concentrations may have a severe impact on the biota of Lake Baikal. If deep-water exchange is reduced drastically during severe climatic conditions, anoxic conditions may develop and possibly lead to mass extinction on a time scale on the order of 100 years or more.

\section{References}

Hohmann R., R. Kipfer, F. Peeters, G. Piepke, D. M. Imboden and M. N. Shimaraev, 1997, Processes of deep water renewal in Lake Baikal. Limnol. 
Oceanogr., 42, 841-855.

Hohmann R., M. Hofer, R. Kipfer, F. Peeters and D. M. Imboden, 1998, Distribution of helium and tritium in Lake Baikal. J. Geophys. Res. 103, 12823-12838.

Imboden D. M., 1994, Deep water formation: The physical mystery of Lake Baikal. Baikal as a natural laboratory for global change, 1, 21-22 (abstr.).

Kipfer R., W. Aeschbach-Hertig, M. Hofer, R. Hohmann, D. M. Imboden, H. Baur, V. Golubev and J. Klerkx, 1996, Bottomwater formation due to hydrothermal activity in Frolikha Bay, Lake Baikal, eastern Siberia. Geochim. Cosmochemi. Acta 60, 961-971.

Peeters F., G. Piepke,' R. Kipfer, R. Hohmann and D. M. Imboden, 1996, Description of stability and neutrally buoyant transport in freshwater lakes. Limnol. Oceanogr., 41, 1711-1724.

Peeters F., G. Piepke, R. Kipfer, R. Hohmann and D. M. Imboden, 1997, Modelling transport rates in Lake Baikal: gas exchange and deep water renewal. Environ. Sci. Technol., 31, 2973-2982.

Shimaraev M. N., N. G. Granin and A. A. Zhadanov, 1993, Deep ventilation of Lake Baikal due to spring thermal bars. Limnol. Oceanogr. 38, 1068-1072.

Shimaraev M. N., V. I. Verbolov, N. Granin and P. P. Sherstayankin, 1994 , Physical limnology of Lake Baikal: a review. Irkutsk, Okayama, $80 \mathrm{pp}$

Weiss R. F., E. C. Carmack and V. M. Koropalov, 1991, Deep-water renewal and biological production in Lake Baikal. Nature 349, 665-669.

Wüest A., A. Aeschbach-Hertig, H. Baur, M. Hofer, R. Kipfer and M. Schurter, 1992, Density structure and tritium-helium age of deep hypolimnetic water in the northern basin of Lake Lugano. Aquat. Sci. 54, 205-218. 